\title{
Pterosaur embryo from the Early Cretaceous
}

An impressive fossil discovered in China confirms that pterosaurs were egg-layers.

D inosaur embryos have been discovered all over the world ${ }^{1,2}$, but so far no pterosaur embryos have been reported. Here we describe a Chinese fossil from the Early Cretaceous period containing an embryo that is unambiguously a pterosaur. The embryonic skeleton, which is exquisitely preserved in its egg, is associated with eggshell fragments, wing membranes and skin imprints. This discovery confirms that pterosaurs were egg-layers and sheds new light on our understanding of pterosaur development.

The fossil was collected from the lacustrine shales of the Jingangshan Bed of the upper Yixian Formation at Jingangshan in western Liaoning, China. ${ }^{40} \mathrm{Ar} /{ }^{39} \mathrm{Ar}$ dating ${ }^{3}$ shows the fossil-bearing deposit is 121 million years old, indicating that the fossil is from the late Early Cretaceous (Aptian) period. Associated fossils from the same horizon include Lycoptera, Manchurochelys, Yabeinosaurus and some undescribed pterodactyloids and birds ${ }^{4}$.

The embryo is preserved in the brown part and counterpart of an almost complete egg (Fig. 1a, b). There is a distinctive elliptical margin that is markedly different from the yellowish-grey matrix. The egg has a maximum length of $53 \mathrm{~mm}$ and a maximum width of $41 \mathrm{~mm}$.

The skull is preserved in ventral view, whereas the postcranial bones are in dorsal view. The skull is curved backwards, forming an inverse U-shape with the vertebral column, which extends along the long axis of the egg. The forelimbs are tightly folded. Both the lower jaw and the limb bones are characterized by less ossified epiphyses and an immature grainy texture ${ }^{5}$. The scapula is not fused with the coracoid. The vertebral column, carpal bones and pedal digits are also incompletely ossified.

The skeleton has a partial skull and nearly complete postcranial bones (Fig. 1a-d). The lower jaws are robust, with two slender and slightly curved teeth. At least five dorsal vertebrae are preserved. The humerus is strong, with a non-rectangular deltopectoral crest. The wing metacarpal is well developed, and is slightly shorter than the humerus. The length of the femur nearly equals the length of the humerus, and is about three-quarters of the length of the tibia. Metatarsals I-IV are relatively small and slender; metatarsal III is short and about $20 \%$ of the length of the tibia.

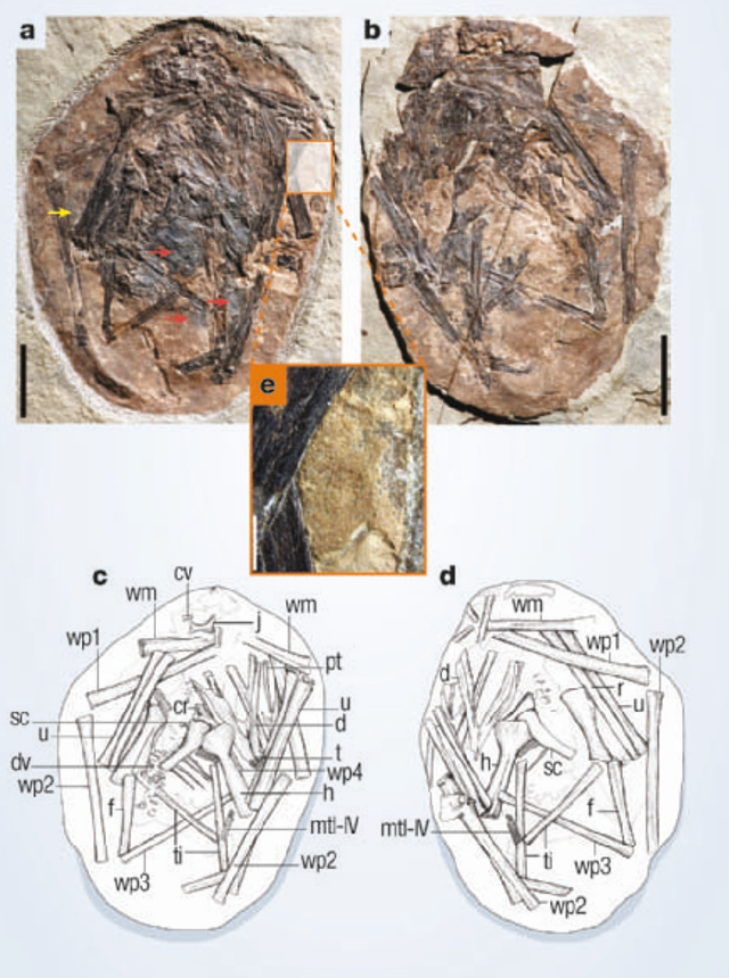

Figure 1 Pterosaur embryo inside an egg from the Early Cretaceous period from Liaoning, China (IVPP V13758). a-d, Photographs of part (a) and counterpart (b) of the fossil and their corresponding line drawings (c, d; not to scale). Red arrows indicate skin imprints and the yellow arrow indicates the fibres of the wing membrane. Scale bar, $10 \mathrm{~mm}$. e, Close-up of the papilla-like ornamentation of the eggshell (corresponding to orange frame in a). Scale bar, $2 \mathrm{~mm}$. Abbreviations in c, d: cr, coracoid; cv, cervical vertebra; d, dentary; dv, dorsal vertebra; femur; h, humerus; j, jugal; mtl-IV, metatarsals I-IV; pt, pteroid; r, radius; sc, scapula; t, tooth; tibia; u, ulna; wp1-4, first to fourth phalanges of the wing digit; wm, wing metacarpal.

extensively distributed in the fossil, and may assist identification of the embryo. Wing membrane fibres are also preserved, together with some wing phalanges. Large patches of skin imprints are preserved, mainly in the posterior part of the body. Preservation of such delicate tissues with the skeleton and eggshell probably indicates that the embryo was killed and deposited quickly as a result of a natural disaster, such as a volcanic eruption ${ }^{4}$.

This embryonic skeleton from the Jehol Biota is larger than the smallest baby Pterodactylus, from Solnhofen, which had proper flight capability and a wingspan of about $18 \mathrm{~cm}$ (ref. 7). The Liaoning embryo has a wingspan of $27 \mathrm{~cm}$, indicating that the embryo would have grown up into a medium-tolarge pterosaur.

The Liaoning fossil has preserved nearly all the skeletal elements and clear imprints of the wing membranes, indicating that this pterosaur embryo was probably enjoying its last few days in the egg before hatching out to walk on the Early Cretaceous earth.

Xiaolin Wang, Zhonghe Zhou Institute of Vertebrate Paleontology and Paleoanthropology, Chinese Academy of Sciences, PO Box 643, Beijing 100044, China

e-mail:xlinwang@263.net

The embryo can undoubtedly be identified as that of a pterosaur because the preserved skeleton shows an extremely elongated fourth finger and a stout humerus with a well developed deltopectoral process ${ }^{6}$. The remarkably elongated wing metacarpal indicates that it is a pterodactyloid ${ }^{7}$.

We could assign the embryo to the Ornithocheiridae because of such features as its relatively short metatarsals (less than $25 \%$ of the length of the humerus) and the rounded, flange-shaped deltopectoral crest of the humerus ${ }^{8,9}$. Of the pterosaurs that have been discovered from the Yixian Formation $^{10,11}$, Haopterus most resembles this embryo. However, allometric growth during pterosaur development means we must be cautious about making direct ratio comparisons between embryonic and adult elements, so it is uncertain whether this fossil can be assigned to any known taxa of the Ornithocheiridae.

Preserved patches of eggshell showing papilla-like ornamentation (Fig. 1e) are
1. Norell, M. A. et al. Science 266, 779-782 (1994).

2 Chiappe, L. M. et al. Nature 396, 258-261 (1998).

3. Smith, P. E. et al. Can. J. Earth Sci. 32, 1426-1431 (1995).

4. Wang, X. \& Zhou, Z. in The Jehol Biota (eds Chang, M., Chen, P., Wang, Y.-Q. \& Wang, Y.) 19-36 (Shanghai Scientific \& Technical, Shanghai, 2003)

5. Bennett, S. C. Paleobiology 19, 92-106 (1993).

6. Unwin, D. M. in Evolution and Palaeobiology of Pterosaurs (eds Buffetaut, E. \& Mazin, J. M.) Geol. Soc. Lond., Sp. Publ. 217, 139-190 (2003).

7. Wellnhofer, P. The Illustrated Encyclopedia of Pterosaurs 1-192 (Salamander, London, 1991)

8. Unwin, D. M. Mitt. Mus. Naturk.. Berl., Geowiss. Reihe 4, 189-221 (2001)

9. Unwin, D. M., Lü, J. \& Bakhurina, N. N. Mitt. Mus. Naturk. Berl., Geowiss. Reihe 3, 181-206 (2000).

10. Ji, S., Ji, Q. \& Padian, K. Nature 398, 573-574 (1999). 11. Wang, X. \& Lü, J. Chinese Sci. Bull. 46, 1112-1117 (2001). Competing financial interests: declared none.

\section{brief communications arising online}

\section{www.nature.com/bca}

Palaeobiology: Dutch diaries and the demise of the dodo

J. P. Hume, D. M. Martill \& C. Dewdney

(doi:10.1038/nature02688) 